\title{
Colletotrichum acidae sp. nov. from northern Thailand and a new record of C. dematium on Iris sp.
}

\section{Samarakoon $\mathrm{MC}^{1,2,3}$, Peršoh $\mathrm{D}^{4}$, Hyde $\mathrm{KD}^{1,5^{*}}$, Bulgakov $\mathrm{TS}^{6}$, Manawasinghe IS $^{1,7}$, Jayawardena $\mathbf{R S}^{1}$, Promputtha $\mathbf{I}^{2,8}$}

${ }^{1}$ Center of Excellence in Fungal Research, Mae Fah Luang University, Chiang Rai 57100, Thailand

${ }^{2}$ Department of Biology, Faculty of Science, Chiang Mai University, Chiang Mai 50200, Thailand

${ }^{3}$ Mushroom Research Foundation, 128 M.3 Ban Pa Deng T. Pa Pae, A. Mae Taeng, Chiang Mai 50150, Thailand

${ }^{4}$ Department of Geobotany, Ruhr-University Bochum, Universitätsstrasse 150, 44801 Bochum, Germany

${ }^{5}$ Key Laboratory for Plant Diversity and Biogeography of East Asia, Kunming Institute of Botany, Chinese Academy of Sciences, 132 Lanhei Road, Kunming 650201, China

${ }^{6}$ Russian Research Institute of Floriculture and Subtropical Crops, 2/28 Yana Fabritsiusa Street, Sochi 354002, Krasnodar region, Russia

${ }^{7}$ Beijing Key Laboratory of Environmental Friendly Management on Fruits Diseases and Pests in North China, Institute of Plant and Environment Protection, Beijing Academy of Agriculture and Forestry Sciences, Beijing 100097, People's Republic of China

${ }^{8}$ Environmental Science Research Center, Faculty of Science, Chiang Mai University, 50200, Thailand

Samarakoon MC, Peršoh D, Hyde KD, Bulgakov TS, Manawasinghe IS, Jayawardena RS, Promputtha I 2018 - Colletotrichum acidae sp. nov. from northern Thailand and a new record of $C$. dematium on Iris sp. Mycosphere 9(3), 583-597, Doi 10.5943/mycosphere/9/3/9

\begin{abstract}
Colletotrichum has a wide host range and distribution and its species are pathogens, endophytes and saprobes. Investigations of Colletotrichum species in both tropical and temperate regions are still needed as much novelty remains to be discovered. A multi-locus phylogenetic analyses of ITS, GAPDH, CHS-1, ACT and TUB2 sequence data combined with morphology, revealed a new species, $C$. acidae on Phyllanthus acidus, belonging to the $C$. truncatum species complex. A new Russian record for $C$. dematium on Iris sp. was also revealed. A combination of sequence data handling tools in the ARB database was used for the phylogenetic analyses and is provided in the appendix. The new species is described and illustrated in this paper and compared with taxa in the $C$. truncatum species complex.
\end{abstract}

Key words -1 new species - molecular phylogeny - saprobe - taxonomy

\section{Introduction}

Colletotrichum species (Glomerellaceae) are one of the ten economically most important fungal plant pathogens worldwide (Dean et al. 2012). They also occur as symptomless endophytes in living plants and as saprobes of dead plant material in aquatic and terrestrial habitats (Hyde et al. 2009a, Wikee et al. 2011, Cannon et al. 2012, Jayawardena et al. 2016a, Wijayawardene et al. 2017). However, the same species may show different nutritional modes based on the environmental conditions in which they occur (Jayawardena et al. 2016b).

Colletotrichum was established by Corda (1831) to accommodate $C$. lineola, the type species for this genus (Damm et al. 2009) and belongs in Glomerellaceae, Glomerellales 
(Maharachchikumbura et al. 2016). Morphological identification and species delimitation in Colletotrichum is challenging as their sexual morphs are not often produced and the asexual morphs have few distinguishing characters (Hyde et al. 2009b, Cannon et al. 2012). This has resulted in considerable confusion concerning the species concepts (Cannon et al. 2012, Jayawardena et al. 2016b). However, Cai et al. (2009), Hyde et al. (2009b) proposed to use a combination of phylogeny, morphology, geographical and ecological information in order to resolve species boundaries in the genus. Recent studies have revealed 196 Colletotrichum species, of which 184 species are grouped in eleven species complexes (Jayawardena et al. 2016a, 2017, Buyck et al. 2017, Marin-Felix et al. 2017, Sharma et al. 2017, Tibpromma et al. 2017, 2018).

The plant genus Phyllanthus (Phyllanthaceae) comprises 750-1,200 species with a remarkable diversity. Among those, Phyllanthus acidus (L.) Skeels, commonly known as the Otaheite gooseberry is a popular fruit mainly distributed in Asia (Tharakan 2012). A recent study has revealed that there is a great fungal diversity, especially endophytes, on P. acidus (Manogaran et al. 2017). However, only a few Colletotrichum species have been reported from this host in Southeast Asia. Leaf anthracnose on Phyllanthus acidus caused by Colletotrichum phyllanthi was reported in India (Pai 1966, Damm et al. 2012, Sharma \& Shenoy 2013). Farr \& Rossman (2017) (https://nt.ars-grin.gov/fungaldatabases/fungushost/fungushost.cfm) list C. gloeosporioides from Phyllanthus emblica in China (Zhuang 2001) and P. reticulatus in Myanmar (Thaung 2008), as well as an unidentified Colletotrichum sp. from P. acidus in India (Mathur 1979).

Among the most popular garden flowers globally, the genus Iris (Iridaceae) comprises around 300 species which are found mainly in the north temperate region. Their aesthetic value is affected by fungal diseases making various discolorations, spots and necrotic lesions (Kowalik \& Krasny 2009). Several Colletotrichum species, such as $C$. circinans, $C$. coccodes, $C$. dematium, $C$. gloeosporioides, $C$. liliacearum and $C$. tofieldiae have been reported on Iris species from different regions worldwide as pathogens, saprobes or endophytes (Shivas et al. 2016, Liu et al. 2017, Farr \& Rossman 2017) (https://nt.ars-grin.gov/fungaldatabases/fungushost/fungushost.cfm).

This study expands the investigation of Colletotrichum species on Phyllanthus and Iris species. Based on multi-locus phylogeny and morphology, we describe a new species, Colletotrichum acidae, occurring on a decaying rachis of Phyllanthus acidus in northern Thailand. In addition, we provide a new country record for $C$. dematium isolated from Iris species in Russia.

\section{Materials \& Methods}

\section{Collection, isolation and morphological studies}

A dead rachis of Phyllanthus acidus on the road side north of Muang, Muang Chiang Rai district, Thailand and dead flower-bearing stems of Iris sp. from the Subtropical Botanical Garden of Kuban, Sochi, Krasnodar region, Russia were collected and received during 2016-2017.

Specimens were placed in paper bags and dried at room temperature for two days to avoid unwanted fungal growth, insect and mite infestations. Morphological characters such as acervuli on natural substrate (size, shape), conidia, conidiophore, setae (size, shape, colour) and appressoria (size, shape, colour) (Cai et al. 2009) were examined using a stereo microscope (SteREO Discovery v8) attached with Axio Cam ERc5s and Nikon ECLIPSE Ni-U compound microscope (Nikon, Tokyo, Japan) attached with a Canon EOS 600D camera (Canon Inc., Tokyo, Japan). Specimens were mounted in sterile water. The measurements were made with the Tarosoft (R) Image Frame Work program. Mean values and standard deviations $(\alpha=0.05)$ were calculated and presented as (minimum-maximum) $(\overline{\mathrm{x}} \pm \mathrm{SD})(\mathrm{n}=$ number of measurements). Images were used for figures and processed with Adobe Photoshop CS6 software (Adobe Systems Inc).

Pure fungal colonies were obtained through single spore isolation as described by Chomnunti et al. (2014). Germinating spores were transferred aseptically to Potato Dextrose Agar (PDA). The cultures were incubated at $25-30{ }^{\circ} \mathrm{C}$ for $4-6$ weeks with frequent observations. The type specimens are deposited in the Mae Fah Luang University Herbarium (MFLU), Chiang Rai, Thailand and Herbarium of Kunming Institute of Botany (KUN), Chinese Academy of Sciences, Kunming, 
China. Ex-type cultures are deposited in the Culture Collection at Mae Fah Luang University (MFLUCC) and International Collection of Microorganisms from Plants (ICMP), New Zealand. New taxa were linked with Facesoffungi and Index Fungorum databases as explained in Jayasiri et al. (2015) and Index Fungorum (2018).

\section{DNA extraction, PCR amplification and sequencing}

Fresh mycelium scraped from the margin of colonies on PDA plates (incubated at $28{ }^{\circ} \mathrm{C}$ for 4 weeks) and aseptically isolated acervuli were used for total genomic DNA extraction. PCR amplifications were carried out by using the primers ITS1/ITS4 (White et al. 1990), GDF/GDR (Templeton et al. 1992), CHS79F/CHS345R, ACT512F/ACT783R (Carbone \& Kohn 1999) and BT1/BT2 primers (O’Donnell \& Cigelnik 1997), to obtain sequences of the Internal transcribed spacer region (ITS) of the rRNA gene and of the genes coding for glyceraldehyde-3-phosphate dehydrogenase (GAPDH), chitin synthase 1 (CHS-1), actin (ACT) and $\beta$-tubulin (TUB2) respectively.

A total volume of $25 \mu \mathrm{l}$ PCR mixture contained TaKaRa Ex-Taq DNA polymerase $0.3 \mu$, $12.5 \mu \mathrm{l}$ of $2 \times$ PCR buffer with $2.5 \mu \mathrm{l}$ of dNTPs, $1 \mu \mathrm{l}$ of each primer, $9.2 \mu$ l of double-distilled water and 100-500 ng of DNA template followed thermal cycle programmes described by Weir et al. (2012). All the PCR products were visualized by staining with ethidium bromide (EtBr) on 1.2\% agarose gels. Successful PCR products were purified according to the manufacturer's instructions of a Qiagen purification kit (Qiagen, USA) and sequenced in Sunbiotech Company, Beijing, China.

\section{Phylogenetic analyses}

Obtained sequences were subjected to BLAST search in GenBank (https://blast.ncbi.nlm.nih.gov/Blast.cgi) and coherence of the results was controlled based on morphological characters. Reference sequence data (Tables 1, 2) were downloaded and imported into the ARB database and program package (Ludwig et al. 2004) together with the newly generated sequences and analysed following the ARB workflow (Perera et al. 2018, Thambugala et al. 2018). Individual loci were aligned using default settings of MAFFT (Katoh et al. 2009) as implemented in ARB applying an offset value of 0.5. The aligned sequences were improved when necessary by manual adjustments in ARB (Appendix 1).

ARB databases including all phylogenetic trees and corresponding alignments are available on the SILVA project website (https://www.arbsilva.de/no_cache/download/archive/publications/fungal_taxa/).

Table 1 Taxa (Colletotrichum truncatum species complex) used in the phylogenetic analyses.

\begin{tabular}{|c|c|c|c|c|c|c|c|}
\hline Taxa & Isolate & ITS & GAPDH & CHS-1 & ACT & TUB2 & Refe \\
\hline \multirow[t]{2}{*}{ C. acidae } & \multicolumn{7}{|c|}{ *MFLUCC 17-2659MG996505 MH003691 MH003694 MH003697 MH003700 This study } \\
\hline & *MFLU 18-0233 & MG996506 & MH003692 & MH003695 & MH003698 & MH003701 & This study \\
\hline \multirow[t]{2}{*}{ C. curcumae } & IMI 2889 & & & $\mathrm{U} 22$ & $\mathbf{U} 227$ & GU228 & Damm et a \\
\hline & strai & & & & 10г7 & МЕ278- & \\
\hline \multirow[t]{5}{*}{ C. truncatum } & CBS & GU2 & & GU2 & GU22 & GU2 & 9 \\
\hline & CBS & GU22? & GU2 & GU2 & GU22 & GU228156 & 09 \\
\hline & CBS 120709 & GU227877 & GU228269 & GU22836 & GU2279 & GU228 & $\mathrm{Da}$ \\
\hline & IMI & GU22 & GU2 & $\mathrm{U} 2$ & GU22 & GU2 & 09 \\
\hline & CBS 710.70 & GU227864 & GU228256 & GU228354 & GU227962 & GU2281 & Damm e \\
\hline fusiforme & MFLUCC 12-0437 & КТ290266 & KT290255 & KT290253 & KT290251 & KT290256 & Ariyawansa et al. 2015 \\
\hline
\end{tabular}

BLAST search results and initial morphological studies revealed that the two species investigated in this study belong to Colletotricum truncatum and $C$. dematium species complexes. Therefore, separate analyses were carried out for each complex using only reliably alignable positions present in the majority of the sequences (Table 3). Phylogenetic analyses of the $C$. truncatum species complex were based on individual loci (data accessible at https://www.arbsilva.de/fileadmin/silva_databases/publications/fungal_taxa/Colletotrichum_acidae.arb) and a 
concatenated alignment of ITS, GAPDH, CHS-1, ACT and TUB2. The $C$. dematium species complex was analysed based on individual loci (data accessible at https://www.arbsilva.de/fileadmin/silva_databases/publications/fungal_taxa/Colletotrichum_dematium.arb) and the concatenated alignment of ITS, GAPDH, CHS-1 and ACT followed the alignable base positions (Table 3). We obtained similar backbone tree topologies from individual and concatenated loci trees and considered only concatenated trees for each complex.

Table 2 Taxa (Colletotrichum dematium species complex) used in the phylogenetic analyses.

\begin{tabular}{|c|c|c|c|c|c|c|}
\hline Taxa & Isolate & ITS & GAPDH & CHS-1 & ACT & References \\
\hline \multirow[t]{2}{*}{ C. anthrisci } & CBS 125334 & GU227845 & GU228237 & GU228335 & GU227943 & Damm et al. 2009 \\
\hline & CBS 125335 & GU227846 & GU228238 & GU228336 & GU227944 & Damm et al. 2009 \\
\hline \multirow[t]{3}{*}{ C. circinans } & CBS 221.81 & GU227855 & GU228247 & GU228345 & GU227953 & Damm et al. 2009 \\
\hline & CBS 111.21 & GU227854 & GU228246 & GU228344 & GU227952 & Damm et al. 2009 \\
\hline & CBS 351.73/ATCC 24488 & GU227858 & GU228250 & GU228348 & GU227956 & Damm et al. 2009 \\
\hline \multirow[t]{5}{*}{ C. dematium } & CBS 125.25 & GU227819 & GU228211 & GU228309 & GU227917 & Damm et al. 2009 \\
\hline & CBS 125340 & GU227820 & GU228212 & GU228310 & GU227918 & Damm et al. 2009 \\
\hline & IMI 350847 & GU227825 & GU228217 & GU228315 & GU227923 & Damm et al. 2009 \\
\hline & CBS 115524/STE-U4078 & GU227826 & GU228218 & GU228316 & GU227924 & Damm et al. 2009 \\
\hline & *MFLU 18-0234 & MG996507 & MH003693 & MH003696 & МH003699 & This study \\
\hline \multirow[t]{3}{*}{ C. eryngiicola } & MFLUCC 17-0318 & KY792726 & KY792723 & KY792720 & KY792717 & Buyck et al. 2017 \\
\hline & MFLUCC 17-0317 & KY792725 & KY792722 & KY792719 & KY792716 & Buyck et al. 2017 \\
\hline & KUMCC 17-0071 & KY792724 & KY792721 & KY792718 & KY792715 & Buyck et al. 2017 \\
\hline C. fructi & CBS 346.37 & GU227844 & GU228236 & GU228334 & GU227942 & Damm et al. 2009 \\
\hline \multicolumn{2}{|c|}{ C. hemerocallidis CDLG5 } & JQ400005 & JQ400012 & JQ399998 & JQ399991 & Yang et al. 2012 \\
\hline & CDLN6 & JQ400006 & JQ400013 & JQ399999 & JQ399992 & Yang et al. 2012 \\
\hline & CDLN7 & JQ400007 & JQ400014 & JQ400000 & JQ399993 & Yang et al. 2012 \\
\hline \multirow{4}{*}{$\begin{array}{l}\text { C. insertae } \\
\text { C. lineola }\end{array}$} & MFLU 15-1895 & KX618686 & KX618684 & KX618683 & KX618682 & Hyde et al.2016 \\
\hline & CBS 125337 & GU227829 & GU228221 & GU228319 & GU227927 & Damm et al. 2009 \\
\hline & CBS 282.85 & GU227843 & GU2 & GU228333 & GU227941 & Damm et al. 2009 \\
\hline & CBS 125329 & GU227833 & GU228225 & GU228323 & GU227931 & Damm et al. 2009 \\
\hline \multirow{4}{*}{$\begin{array}{l}\text { C. menispermi } \\
\text { C. quinquefoliae } \\
\text { C. sambucicola }\end{array}$} & MFLU 14-0625 & KU242357 & KU242356 & KU242355 & KU242353 & Li et al. 2016 \\
\hline & MFLU 14-0626 & KU236391 & KU236390 & N/A & KU236389 & Li et al. 2016 \\
\hline & MFLUCC 16-1388 & KY098781 & KY098780 & KY098779 & KY098778 & Tibpromma et al. 2017 \\
\hline & strain 2902-2 & KY595193 & KY5 & KY595191 & KY595190 & Tibpromma et al. 2017 \\
\hline \multirow{4}{*}{$\begin{array}{l}\text { C. sedi } \\
\text { C. sonchicola }\end{array}$} & MFLUCC 14-1002 & KM974758 & 3 KM974755 & KM974754 & KM974756 & Liu et al. 2015 \\
\hline & JZB330117 & KY962756 & KY962753 & KY962750 & KY962747 & Jayawardena et al. 2017 \\
\hline & MFLUCC 17-1299 & KY962757 & KY962754 & KY962751 & KY962748 & Jayawardena et al. 2017 \\
\hline & MFLUCC17-1300 & KY962758 & KY962755 & KY962752 & KY962749 & Jayawardena et al. 2017 \\
\hline \multirow[t]{3}{*}{ C. spinaceae } & CBS 128.57 & GU227847 & GU228239 & GU228337 & GU227945 & Damm et al. 2009 \\
\hline & IMI 104607 & GU227850 & GU228242 & GU228340 & GU227948 & Damm et al. 2009 \\
\hline & CBS 125347/DAOM2126 & GU227851 & GU228243 & GU228341 & GU227949 & Damm et al. 2009 \\
\hline
\end{tabular}

Abbreviations (Tables 1, 2): ATCC American Type culture collection, CBS Culture collection of the Centraalbureau voor Schimmelcultures, Fungal Biodiversity Centre, Utrecht, The Netherlands, DAOM National Mycological Herbarium, Ottawa, Canada, IMI Culture collection of CABI Europe UK Centre, Egham, UK, KUMCC Kunming Institute of Botany Culture Collection, MFLU Herbarium of Mae Fah Luang University, Chiang Rai, Thailand, MFLUCC Mae Fah Luang University Culture Collection, Chiang Rai, Thailand, STE-U Culture collection of the Department of Plant Pathology, University of Stellenbosch, South Africa. Type strains are bold. *Sequence data obtained in this study. "N/A" sequence is unavailable.

Table 3 Alignable positions of each region in ARB.

\begin{tabular}{lccc}
\hline \multicolumn{1}{c}{ Loci } & Reference sequence & Alignable positions* & No. of bases \\
\hline Colletotrichum truncatum & species complex (C. truncatum CBS 151.35) & 473 \\
ITS & GU227862 & $21-494$ & 235 \\
GAPDH & GU228254 & $19-254$ & 211 \\
CHS-1 & GU228352 & $40-251$ & 266 \\
ACT & GU227960 & $22-248$ & 440 \\
TUB2 & GU228156 & $47-230,231-314,315-487$ & \\
\hline
\end{tabular}


Table 3 Continued.

\begin{tabular}{llll}
\hline \multicolumn{1}{c}{ Loci } & Reference sequence & Alignable positions* & No. of bases \\
\hline C. dematium & species complex $($ C. dematium CBS 125.25) & \\
ITS & GU227819 & $31-515$ & 484 \\
GAPDH & GU228211 & $26-32,33-129,130-150,151-260$ & 234 \\
CHS-1 & GU228309 & $45-251$ & 206 \\
ACT & GU227917 & $1-35,36-69,70-84,85-173,174-213,214-234$ & 234 \\
\hline
\end{tabular}

*The alignable base positions are based on original sequences in the GenBank

Maximum likelihood (ML) analyses (RAxML v8.2.8) (Stamatakis 2014) were performed as implemented in ARB applying the GTRGAMMA+I model of rate distribution as default parameter. Bootstrap support was calculated by rapid bootstrap analysis of 1,000 replicates using RAxML. Bayesian analyses were performed using MRBAYES v2 (Huelsenbeck \& Ronquist 2001) with invariable site rate variation, six number of substitution types, four rate categories for the gamma distribution. Four chains were run for $1,000,000$ MCMC generations with every $100^{\text {th }}$ tree sampled and the analyses were automatically closed when split frequencies fell below 0.01 . The split frequencies were 0.002 and 0.009 for the analyses of Colletotricum truncatum and $C$. dematium species complexes respectively. The first $25 \%$ of the resulted trees of each were discarded with default parameter settings. The output trees were visualized by using Xfig v.3.2 patchlevel 5c (Protocol 3.2, http://mcj.sourceforge.net/) and final layouts were done with CorelDRAW Graphics Suite X6.

\section{Results}

\section{Phylogenetic analyses}

The sequence data obtained from strains MFLUCC 17-2659 and MFLU 18-0233 in this study were identical for all loci and each had closely related sequences to the Colletotrichum truncatum species complex in BLAST analyses. The concatenated alignment for the complex comprised ten strains representing four taxa. The individual and concatenated un-rooted trees were similar in topology. C. fusiforme and the new taxa, both known from Thailand, were sister taxa (100\% ML/1.00 PP). This clade formed a basal clade to $C$. truncatum with maximum statistical supports (100\% ML, Fig. 1).

The sequence matrix of the $C$. dematium species complex comprised of 32 taxa. The strain in this study clustered with $C$. dematium with low statistical support $(53 \% \mathrm{ML} / 0.85 \mathrm{PP})$ in the concatenated tree (Fig. 2).

\section{Taxonomy}

Colletotrichum acidae Samarak. \& K.D. Hyde, sp. nov.

Fig. 3

Index Fungorum number: IF554277; Facesoffungi number: FoF04122

Etymology - based on the host species from which it was collected.

Holotype - MFLU 18-0100

Saprobic on dead Phyllanthus acidus. Asexual morph Conidiomata 95-225 $\mu \mathrm{m}$ $(\overline{\mathrm{x}}=148.8 \pm 45.9) \mu \mathrm{m}(\mathrm{n}=10)$ diam., black, acervulus, oval, solitory. Setae abundant, pale to medium brown, smooth walled, 1-5 septate, 70-170 $\mu \mathrm{m}(\overline{\mathrm{x}}=113.4 \pm 44.6) \mu \mathrm{m}(\mathrm{n}=10)$ long, base cylindrical, 4-10 $\mu \mathrm{m}(\overline{\mathrm{x}}=5.8 \pm 1.7) \mu \mathrm{m}(\mathrm{n}=20)$ diam., tip somewhat acute. Conidiophores hyaline, smoothwalled, simple, 10-20 $\mu \mathrm{m}(\overline{\mathrm{x}}=14.6 \pm 3) \mu \mathrm{m}(\mathrm{n}=20)$ long. Conidiogenous cells $1-2 \mu \mathrm{m}(\overline{\mathrm{x}}=1.5 \pm 0.4)$ $\mu \mathrm{m} \times 2-3.5 \mu \mathrm{m}(\overline{\mathrm{x}}=2.75 \pm 0.4) \mu \mathrm{m}(\mathrm{n}=10)$, hyaline, smooth-walled, cyllindrical to slighty inflated, opening 1-2.5 $\mu \mathrm{m}(\overline{\mathrm{x}}=1.7 \pm 0.3) \mu \mathrm{m}(\mathrm{n}=20)$ diam. Collarette present, $0.4-1.1 \mu \mathrm{m}(\overline{\mathrm{x}}=0.8 \pm 0.2) \mu \mathrm{m}$ $(\mathrm{n}=20) \mu \mathrm{m}$ width, periclinal thickening visible. Conidia $18-30 \mu \mathrm{m}(\overline{\mathrm{x}}=25.1 \pm 2.5) \mu \mathrm{m} \times 2.8-4 \mu \mathrm{m}$ $(\bar{x}=3.4 \pm 0.3) \mu \mathrm{m}(\mathrm{n}=40), \mathrm{L} / \mathrm{W}$ ratio $7.4(\mathrm{n}=40)$, hyaline, smooth or verruculose, aseptate, curved, both sides gradually tapering towards the round to slightly acute apex and truncate base, guttulate. 
Appressoria $11-23 \mu \mathrm{m}(\overline{\mathrm{x}}=15.8 \pm 3.5) \mu \mathrm{m} \times 9-18 \mu \mathrm{m}(\overline{\mathrm{x}}=12 \pm 2.9) \mu \mathrm{m}(\mathrm{n}=10)$, solitary to aggregated, medium to dark brown, smooth-walled, round or oval or irregular. Sexual morph not observed after 4 weeks of incubation.

Culture characteristics - Colonies on PDA reaching $40.4 \mathrm{~mm}$ in 7 days at $28^{\circ} \mathrm{C}$, crateriform with entire margin, olivaceous grey aerial mycelium becoming dull green towards the edge, reverse grey-olivaceous to dull green, concentric.

Material examined - THAILAND, Mae Fah Luang University, Muang, Mueang, Chiang Rai

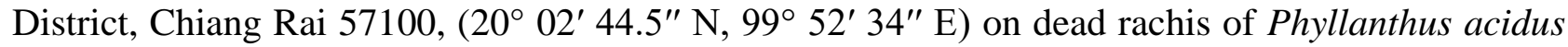
(Phyllanthaceae), 18 May 2017, Milan C. Samarakoon (SAMC004), (MFLU 18-0100 holotype, MFLU 18-0233 paratype), ex-type living culture MFLUCC 17-2659 and ICMP.

Notes - Colletotrichum acidae belongs to the C. truncatum species complex, species of which are characterized by curved conidia with truncate bases and acute, more strongly curved apices (Damm et al. 2009). The ITS based single gene tree also confirmed the close affinity of the species within the complex (data not shown). The multi-locus phylogenetic analyses showed that $C$. acidae is sister to $C$. fusiforme Wijayaw et al. which was isolated from a dead leaf of an undetermined host in Thailand (Ariyawansa et al. 2015). The size of the conidiomata is significantly larger in $C$. acidae $(148 \mu \mathrm{m})$ as compared to $C$. fusiforme $(80 \mu \mathrm{m})$. Setae of $C$. fusiforme are long $(95-225 \mu \mathrm{m})$, dark brown to medium brown and 1-4-septate, while in C. acidae they are comparatively short $(70-170 \mu \mathrm{m})$, pale to medium brown and 1-5-septate setae. Conidia of $C$. fusiforme have a higher $\mathrm{L} / \mathrm{W}$ ration (8.2) than the $C$. acidae (7.4). Also, there is a clear distinction in the appressoria between the two species. Colletotrichum fusiforme has oval appressoria with $\mathrm{L} / \mathrm{W}$ ratio $=3$, while $C$. acidae has round or oval or irregular appressoria with $\mathrm{L} / \mathrm{W}$ ratio $=1.3$ (Fig. $3 \mathrm{~h}-\mathrm{j}$ ). Interestingly, the morphological comparison clearly shows the $C$. acidae has intermediate characters in colour, size and shape as compared to $C$. fusiforme and $C$. truncatum.

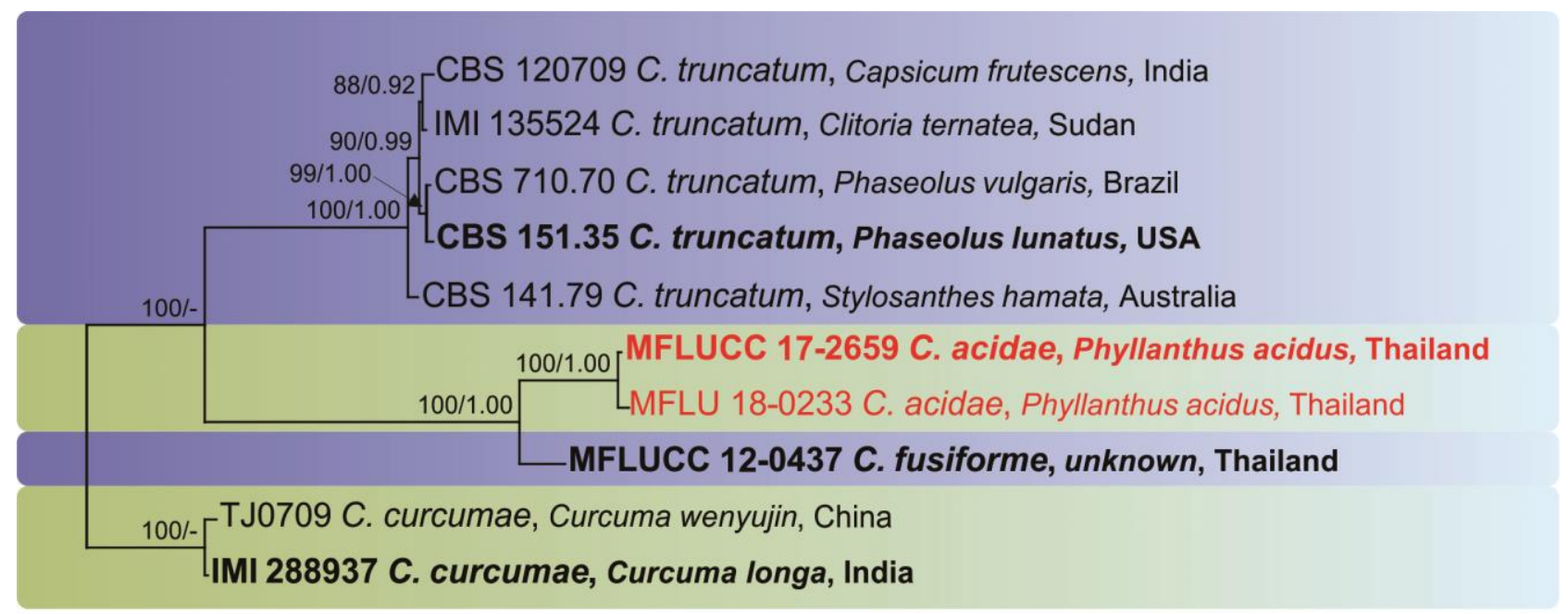

0.10

Figure 1 - Phylogenetic relationships in the Colletotrichum truncatum species complex. The newly proposed species, $C$. acidae, is indicated in red, type strains are in boldface. The culture/strain no, species, host and country are given for each taxon name. ML bootstrap support ( $\geq 50 \%)$ and Bayesian posterior probabilities $(\geq 0.9 \mathrm{PP})$ are mapped to the most likely tree revealed by RAxML from an analysis of the ITS, GAPDH, CHS-1, ACT and TUB2. For the most likely tree ( $\mathrm{InL}=-3188.257132, \alpha=0.176943$, invar $=0.0001, \mathrm{TL}=0.208808$ ) with matrix had 121 distinct alignment patterns, with $3.24 \%$ of undetermined characters or gaps. The base frequencies and substitution rates are as, $\mathrm{A}=0.253179, \mathrm{C}=0.278907, \mathrm{G}=0.233957, \mathrm{~T}=0.233957$; $\mathrm{A}-\mathrm{C}=0.935603$, $\mathrm{A}-\mathrm{G}=3.880499, \mathrm{~A}-\mathrm{T}=1.807471, \mathrm{C}-\mathrm{G}=0.649787, \mathrm{C}-\mathrm{T}=4.970592, \mathrm{G}-\mathrm{T}=1.0000$. 


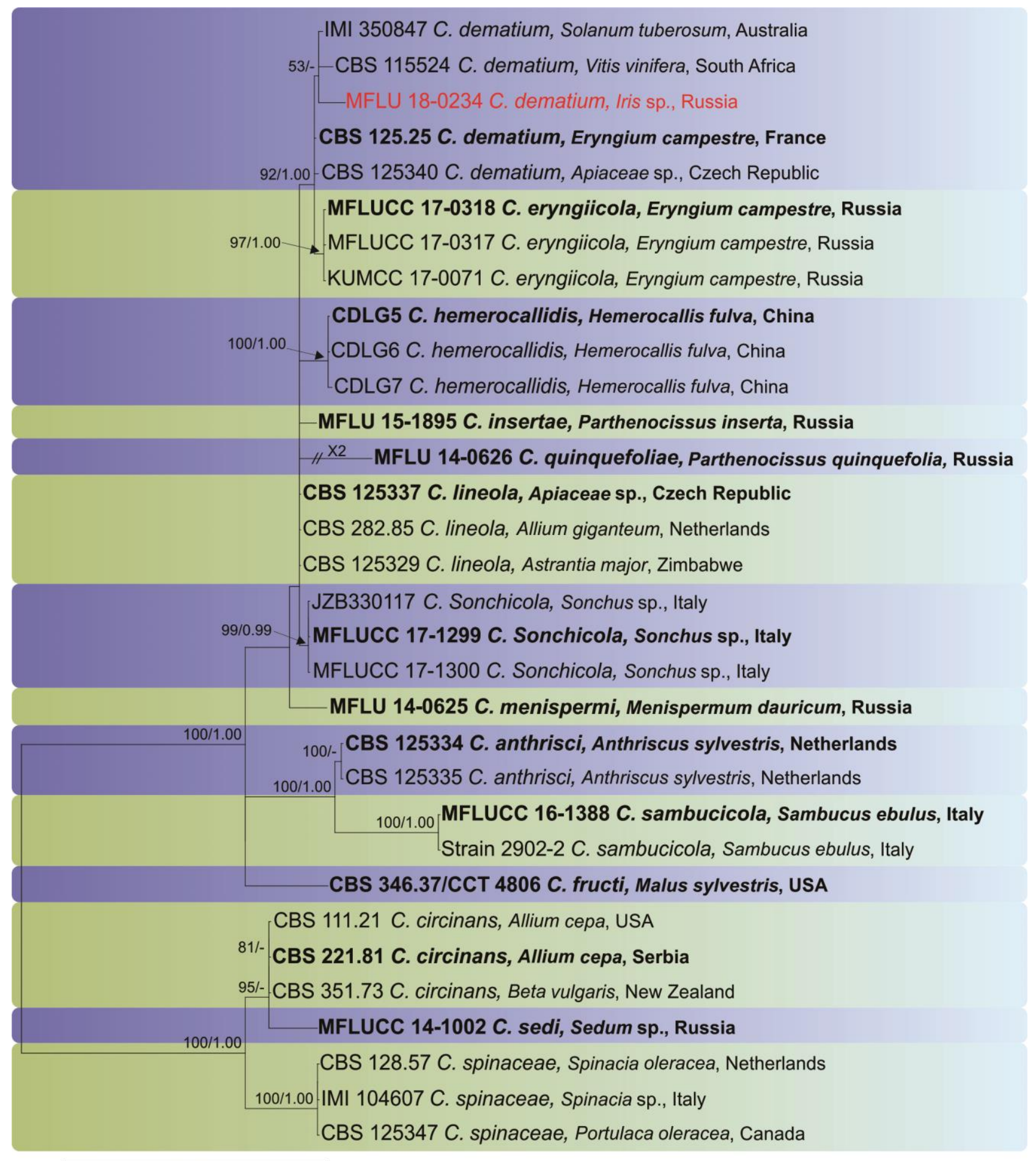

0.10

Figure 2 - Phylogenetic relationships in the Colletotrichum dematium species complex. The newly generated information in red, type strains in boldface. The culture/strain no, species, host and country are given for each taxon name. ML bootstrap support $(\geq 50 \%)$ and Bayesian posterior probabilities $(\geq 0.9 \mathrm{PP})$ are mapped to the most likely tree revealed by Bayesian phylogenetic inference of the ITS, GAPDH, CHS-1 and ACT. For the most likely tree (InL=-3647.953372, $\alpha=0.247151$, invar $=0.0001, T L=0.436903$ ) with matrix had 233 distinct alignment patterns, with $2.72 \%$ of undetermined characters or gaps. The base frequencies and substitution rates are as, $\mathrm{A}=0.241561, \quad \mathrm{C}=0.280178, \mathrm{G}=0.248605, \mathrm{~T}=0.229656 ; \quad \mathrm{A}-\mathrm{C}=1.111599, \quad \mathrm{~A}-\mathrm{G}=3.611166, \quad \mathrm{~A}-$ $\mathrm{T}=0.844507, \mathrm{C}-\mathrm{G}=0.965008, \mathrm{C}-\mathrm{T}=5.259273, \mathrm{G}-\mathrm{T}=1.0000$. 

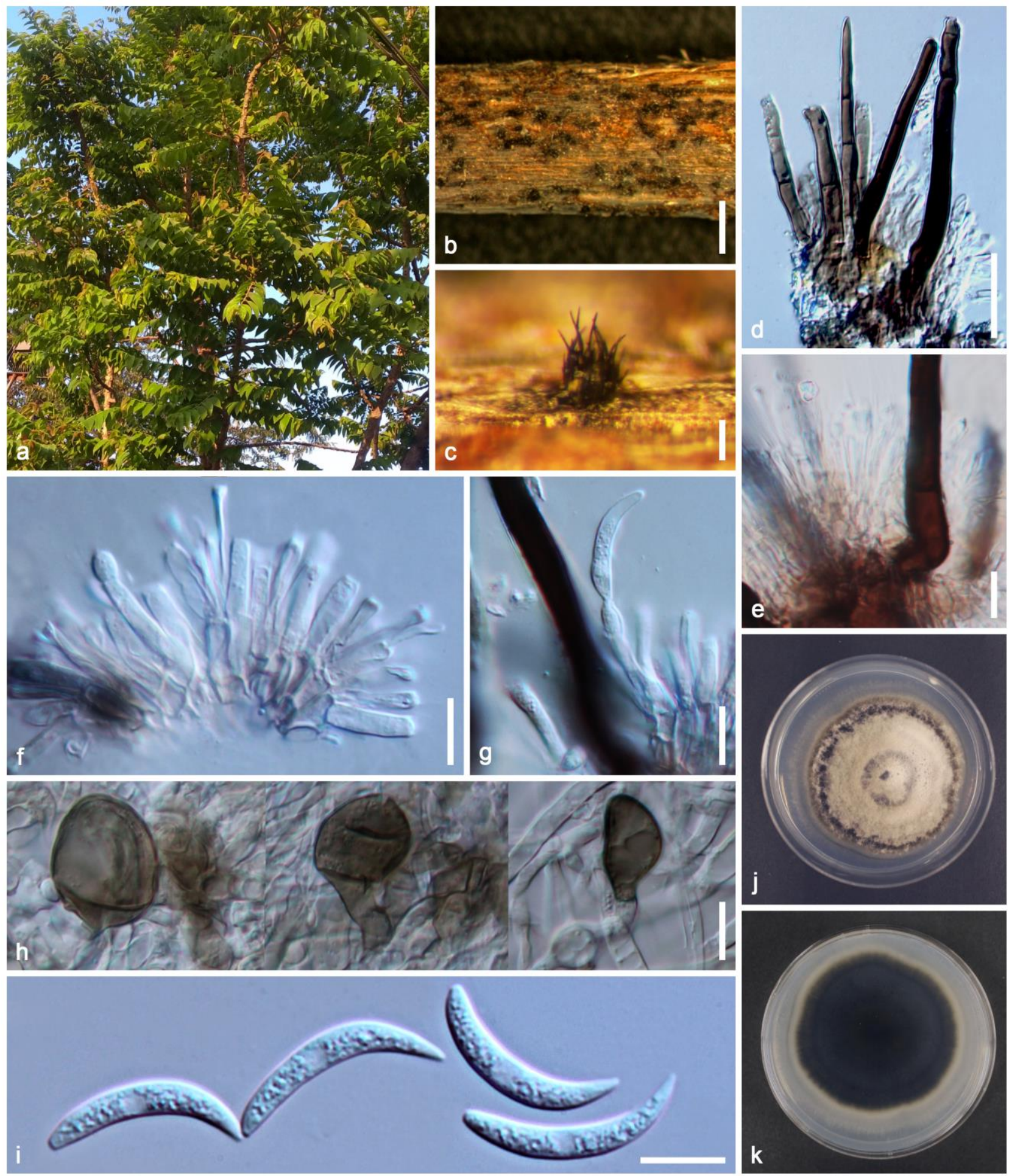

Figure 3 - Colletotrichum acidae (MFLU 18-0100, holotype), a Host. b Specimen with conidiomata. c Appearance of black acervuli on the host. d Brown setae. e Conidiophores with basal setae. f, g Hyaline conidiogenous cells. h Appressoria. i Hyaline conidia. $\mathrm{j}$ Upper view of the colony. $\mathrm{k}$ Reverse view of the colony (4 weeks old). Scale bars $-\mathrm{a}=1000 \mu \mathrm{m}, \mathrm{b}=100 \mu \mathrm{m}$, $\mathrm{d}=20 \mu \mathrm{m}, \mathrm{e}-\mathrm{i}=10 \mu \mathrm{m}$.

The closest BLAST searches with the GAPDH, CHS-1, ACT and TUB2 sequences of MFLUCC 17-2659 were KT290255 (with 92\% identity, 18bp differences), KT290253 (with 99\% identity, 3bp differences), KT290251 (with 94\% identity, 7bp differences) and KT290256 (with 94\% identity, 11 bp differences) from a isolate (MFLU 13-0291) saprobe on dead leaf in Thailand (Ariyawansa et al. 2015). 
Based on both morphological and phylogenetic differences of the isolate, we introduce $C$. acidae as a new species. This is the second known saprobic species belonging to the $C$. truncatum species complex, from Thailand.

Colletotrichum dematium (Pers.) Grove

Fig. 4

Index Fungorum number: IF120313; Facesoffungi number: FoF03598

Saprobic on dead flower-bearing stems of Iris sp. Asexual morph Conidiomata 165-430 $\mu \mathrm{m}$ $(\overline{\mathrm{x}}=285 \pm 75) \mu \mathrm{m}(\mathrm{n}=20)$ diam., black, acervular, oval, solitory. Setae abundant, medium to dark brown, smooth walled, 1-5 septate, 35-140 $\mu \mathrm{m}(\overline{\mathrm{x}}=70 \pm 30) \mu \mathrm{m}(\mathrm{n}=20)$ long, base cylindrical, 4-12 $\mu \mathrm{m}(\overline{\mathrm{x}}=7.3 \pm 2.3) \mu \mathrm{m}(\mathrm{n}=20)$ diam., tip somewhat acute. Conidiophores hyaline, smooth-walled, simple, $(4-8.5 \mu \mathrm{m}(\overline{\mathrm{x}}=6.4 \pm 1.3) \mu \mathrm{m}(\mathrm{n}=15) \mu \mathrm{m}$ long. Conidiogenous cells $5-14.8 \mu \mathrm{m}(\overline{\mathrm{x}}=8.6 \pm 3) \mu \mathrm{m}$ $\times 2.5-5 \mu \mathrm{m}(\overline{\mathrm{x}}=3.2 \pm 0.4) \mu \mathrm{m}(\mathrm{n}=15)$, hyaline, smooth-walled, cyllindrical to slighty inflated. Collarette $0.5-1.1 \mu \mathrm{m}(\overline{\mathrm{x}}=0.8 \pm 0.2) \mu \mathrm{m}(\mathrm{n}=15) \mu \mathrm{m}$ width, periclinal thickening visible. Conidia 21.5-25 $\mu \mathrm{m}(\overline{\mathrm{x}}=23 \pm 0.9) \mu \mathrm{m} \times 2.8-3.6 \mu \mathrm{m}(\overline{\mathrm{x}}=3.2 \pm 0.2) \mu \mathrm{m}(\mathrm{n}=50)$, length/width $7.08 \quad(\mathrm{n}=50)$, hyaline, smooth or verruculose, aseptate, curved, both sides gradually tapering towards the round to slightly acute apex and truncate base. Sexual morph not observed.

Material examined - RUSSIA, Krasnodar Region, Sochi City, Lazarevsky City District, UchDere Village, Subtropical Botanical Garden of Kuban (sanatorium "Belye Nochi”), flowerbed, on dead flower-bearing stems of Iris sp., 7 October 2016, Timur S. Bulgakov SC-088 (MFLU 180234).

Notes - The collection MFLU 18-0234 is morphologically similar to C. eryngiicola Jayaward., Bulgakov \& K.D. Hyde, which share black, oval and solitary acervuli and abundant setae on acervuli with 1-5 septa. However, the sizes of the acervuli have slight differences between the two species (C. eryngiicola 300-700 $\mu \mathrm{m}$, MFLU 18-0234 165-430 $\mu \mathrm{m}$ ) (Buyck et al. 2017). Colletotrichum dematium differs from MFLU 18-0234 with one setae and 3-8 septa (Damm et al. 2009). Colletotrichum dematium, C. eryngiicola and the strain MFLU 18-0234 bear pale brown conidiogenous cells, while showing clear differences in the $\mathrm{L} / \mathrm{W}$ ratio of conidia $(C$. dematium $6, C$. eryngiicola 6.3, MFLU 18-0234 7.08). However, Damm et al. (2009), observed different isolates with different L/W ratio of conidia which are close to the strain MFLU 18-0234 (e.g. IMI 350847 6.7, CBS 125340 5.5).

The GAPDH sequence of MFLU 18-0234 was 100\% identical to JX669425, Colletotrichum dematium strain. The CHS-1 sequence was closer to KX618683 (with 95\% identity, 5bp differences) generated from $C$. insertae on Parthenocissus inserta (L.) Planch. (Vitaceae) from Russia (Hyde et al. 2016). The closest match with the ACT sequence was KY792717 (with 100\% identity) from the strain from Russia (Buyck et al. 2017).

The concatenate phylogenetic analyses revealed that strain MFLU 18-0234 clusters with $C$. dematium with low statistical support. Giving the priority to the phylogenetic analyses the strain MFLU 18-0234 isolated from Iris sp. from Russia is identified as a C. dematium species. Colletotrichum dematium has been recorded on Lilium pensylvanicum Ker Gawl. (Liliaceae) in Asian Russia near border with China (Egorova 2007) and on Tilia cordata Mill. (Malvaceae) in Northwestern European Russia (Mel'nik et al. 2008) and on Vitis vinifera L. (Vitaceae) in Southern European Russia (Jayawardena et al. 2018). However, this is the first record for the occurrence of C. dematium on an Iris sp. in Russia.

\section{Discussion}

Colletotrichum is a worldwide-distributed genus on different hosts (Cannon et al. 2012, Hyde et al. 2014, Jayawardena et al. 2016b). A vast diversity of Colletotrichum species is known from tropical regions (Udayanga et al. 2013). However, plant pathology based Colletotrichum studies are predominant (e.g. Shenoy et al. 2007, Prihastuti et al. 2009, Udayanga et al. 2013, Chowdappa et al. 2014, Krishnapillai \& Wilson-Wijeratnam 2014, Sakinah et al. 2014, He et al. 2016) over endophytes and saprobes. Therefore, the extension of further discoveries towards the endophytic 
and saprobic Colletotrichum species is needed. Also, the relationships between those nutritional modes may also reveal potential opportunistic pathogens hidden as endophytes or saprobes.

A study focussing on $C$. truncatum, $C$. dematium and $C$. gloeosporioides from leguminous plants in Malaysia suggested that the GAPDH locus is critical to resolve intraspecific relationships and closely related species in Colletotrichum (Mahmodi et al. 2014). By considering the phylogenetic analyses and morphological differences, we introduce $C$. acidae as a new species and C. dematium as a new country record in this paper. Furthermore, Colletotrichum acidae and C. fusiforme still known from Thailand are saprobes, which cluster among other pathogenic species. It would be interesting to carry out further research into whether they lost their pathogenicity during evolution, or establish if they may still be pathogenic under different environmental conditions.
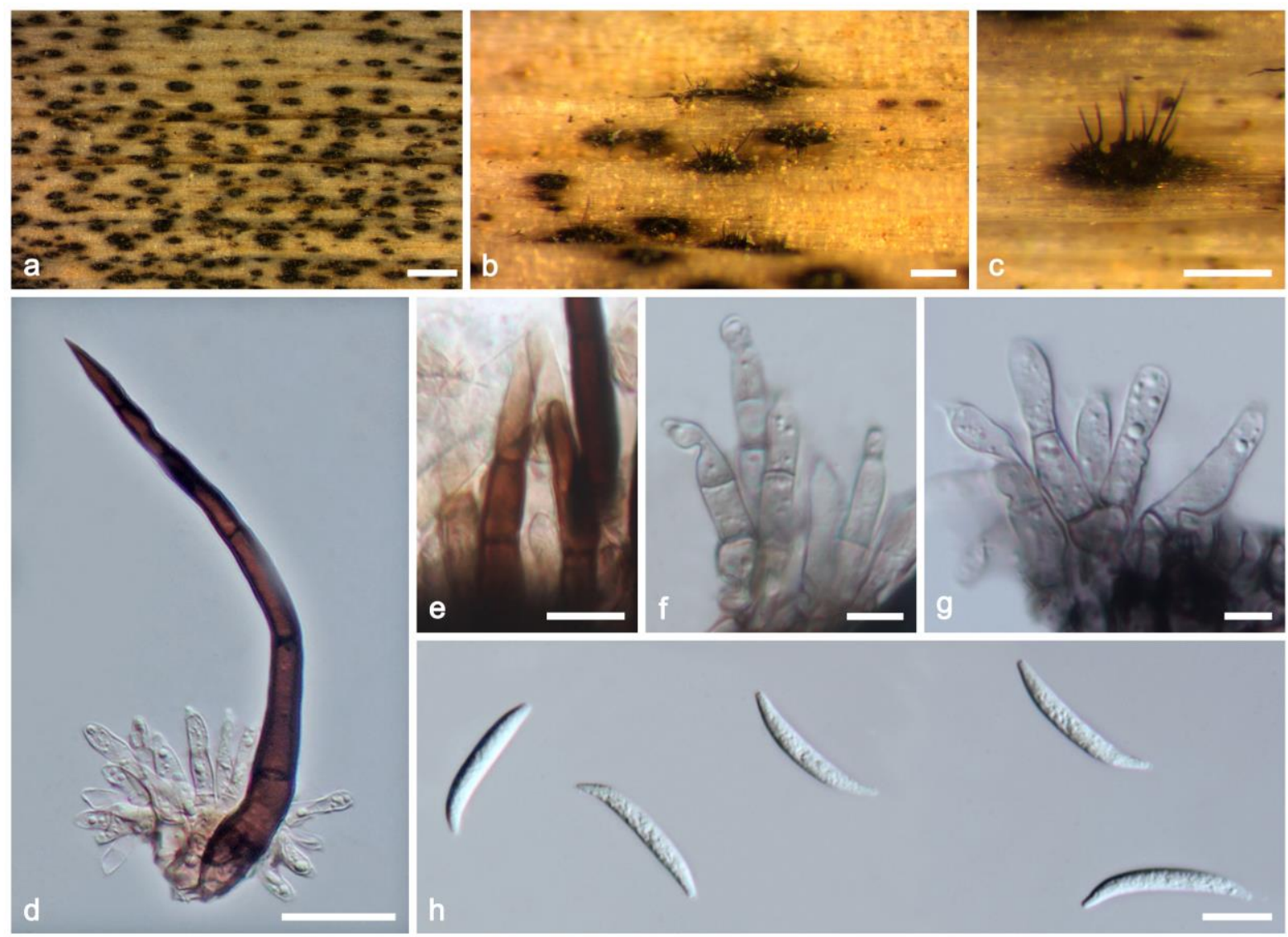

Figure 4 - Colletotrichum dematium (MFLU 18-0234). a Specimen with conidiomata. b, c Black acervuli on the host surface. $d$ Brown setae. e Apex of setae. $\mathrm{f}-\mathrm{g}$ Hyaline conidiogenous cells. $\mathrm{g}$ Hyaline conidia. Scale bars $-\mathrm{a}=1000 \mu \mathrm{m}, \mathrm{b}-\mathrm{c}=200 \mu \mathrm{m}, \mathrm{d}=20 \mu \mathrm{m}, \mathrm{e}, \mathrm{h}=10 \mu \mathrm{m}, \mathrm{f}-\mathrm{g}=5 \mu \mathrm{m}$.

\section{Acknowledgements}

Kevin D. Hyde thanks the Chinese Academy of Sciences, project number 2013T2S0030, for the award of Visiting Professorship for Senior International Scientists at Kunming Institute of Botany. Timur S. Bulgakov is thankful to the Subtropical Botanical Garden of Kuban, Sochi, Russia for scientific support. The authors would like to thank the Thailand Research Fund ("The future of specialist fungi in a changing climate: baseline data for generalist and specialist fungi associated with ants, Rhododendron species and Dracaena species DBG6080013" and "Impact of climate change on fungal diversity and biogeography in the Greater Mekong Sub-region RDG6130001") for funding this research. 


\section{References}

Ariyawansa HA, Hyde KD, Jayasiri SC, Buyck B et al. 2015 - Fungal diversity notes 111-252: taxonomic and phylogenetic contributions to fungal taxa. Fungal Diversity 75, 27-274.

Buyck B, Duhem B, Das K, Jayawardena RS et al. 2017 - Fungal Diversity Profiles 21-30. Cryptogamie Mycologie 38, 101-146.

Cai L, Hyde KD, Taylor PWJ, Weir B et al. 2009 - A polyphasic approach for studying Colletotrichum. Fungal Diversity 39, 183-204.

Cannon PF, Damm U, Johnston PR, Weir BS. 2012 - Colletotrichum current status and future directions. Studies in Mycology 73, 181-213.

Carbone I, Kohn LM. 1999 - A method for designing primer sets for speciation studies in filamentous ascomycetes. Mycologia 91, 553-556.

Chomnunti P, Hongsanan S, Hudson BA, Tian Q et al. 2014 - The Sooty Moulds. Fungal Diversity 66, 1-36.

Chowdappa P, Chethana CS, Pant RP, Bridge PD. 2014 - Multilocus gene phylogeny reveals occurrence of Colletotrichum cymbidiicola and C. cliviae on orchids in North East India. Journal of Plant Pathology 96, 327-334.

Corda ACI. 1831 - Die Pilze Deutschlands. In: Sturm, J. (Eds.) Deutschlands Flora in Abbildungen nach der Natur mit Beschreibungen. Sturm, Nürnberg vol. 3. Abt. 12, 33-64, tab. 21-32.

Damm U, Cannon PF, Woudenberg JHC, Johnston PR et al. 2012 - The Colletotrichum boninense species complex. Studies in Mycology 73, 1-36.

Damm U, Woudenberg JHC, Cannon PF, Crous PW. 2009 - Colletotrichum species with curved conidia from herbaceous hosts. Fungal Diversity 39, 45-87.

Dean R, Van Kan JA, Pretorius ZA, Hammond-Kosack KE et al. 2012 - The top 10 fungal pathogens in molecular plant pathology. Molecular Plant Pathology 13, 414-430.

Egorova LN. 2007 - Anamorphic fungi from Bolshekhekhtsirsky Nature Reserve (Khabarovsk region). Mikologia and Fitopatologia 41, 120-125. [In Russian]

Farr DF, Rossman AY. 2017 - Fungal Databases, Systematic Mycology and Microbiology Laboratory, ARS, USDA. http://nt.ars-grin.gov/fungaldatabases/ (accessed 25 November 2017).

He YY, Chen Q, Wu CW, Yang M, Zhou E. 2016 - Colletotrichum truncatum, a new cause of anthracnose on Chinese flowering cabbage (Brassica parachinensis) in China. Tropical Plant Pathology 41, 183-192.

Huelsenbeck JP, Ronquist F. 2001 - MRBAYES: Bayesian inference of phylogenetic trees. Bioinformatics 17, 754-755.

Hyde KD, Cai L, Cannon PF, Crouch JA et al. 2009a - Colletotrichum-names in current use. Fungal Diversity 39, 147-182.

Hyde KD, Cai L, McKenzie EHC, Yang YL et al. 2009b - Colletotrichum: a catalogue of confusion. Fungal Diversity 39, 1-17.

Hyde KD, Hongsanan S, Jeewon R, Bhat DJ et al. 2016 - Fungal diversity notes 367-491: taxonomic and phylogenetic contributions to fungal taxa. Fungal Diversity 80, 1-270.

Hyde KD, Nilsson RH, Alias SA, Ariyawansa HA et al. 2014 - One stop shop: backbones trees for important phytopathogenic genera: I. Fungal Diversity 67, 21-125.

Index Fungorum. 2018 - Available from: http://www.indexfungorum.org/names/names.asp (accessed 21 January 2018).

Jayasiri SC, Hyde KD, Abd-Elsalam KA, Abdel-Wahab MA et al. 2015 - The faces of fungi database: fungal names linked with morphology, molecular and human attributes. Fungal Diversity 74, 18-357.

Jayawardena RS, Camporesi E, Elgorban AM, Bahkali AH et al. 2017 - A new species of Colletotrichum from Sonchus sp. in Italy. Phytotaxa 314, 55-63. 
Jayawardena RS, Hyde KD, Chethana KWT, Daranagama DA et al. 2018 - Mycosphere Notes 102-168: Saprotrophic fungi on Vitis in China, Italy, Russia and Thailand. Mycosphere 9, 1114.

Jayawardena RS, Hyde KD, Damm U, Cai L et al. 2016a - Notes on currently accepted species of Colletotrichum. Mycosphere 7, 1192-1260.

Jayawardena RS, Hyde KD, Jeewon R, Li XH et al. 2016b - Mycosphere Essay 6: Why it is important to correctly name Colletotrichum species? Mycosphere 7, 1076-1092.

Katoh K, Asimenos G, Toh H. 2009 - Multiple alignment of DNA sequences with MAFFT. In Bioinformatics for DNA sequence analysis 39-64, Humana Press.

Kowalik M, Krasny M. 2009 - Fungi occurring on garden pond plants. Phytopathologia 51, 21-26.

Krishnapillai N, Wilson-Wijeratnam RS. 2014 - First report of Colletotrichum asianum causing anthracnose on Willard mangoes Sri Lanka. New Disease Reports 29, 1.

Li GJ, Hyde KD, Zhao RL, Hongsanan S et al. 2016 - Fungal diversity notes 253-366: taxonomic and phylogenetic contributions to fungal taxa. Fungal Diversity 78, 1-237.

Liu D, Li PL, Li J, Luo X et al. 2017 - First report of Colletotrichum siamense causing anthracnose on Iris tectorum in Sichuan Province of China. Plant Disease 101, 2150-2151.

Liu JK, Hyde KD, Jones EBG, Ariyawansa HA et al. 2015 - Fungal diversity notes 1-110: taxonomic and phylogenetic contributions to fungal species. Fungal Diversity 72, 1-197.

Ludwig W, Strunk O, Westram R, Richter L et al. 2004 - ARB: a software environment for sequence data. Nucleic acids research 32, 1363-1371.

Maharachchikumbura SN, Hyde KD, Jones EBG, McKenzie EHC et al. 2016 - Families of Sordariomycetes. Fungal Diversity 79, 1-317.

Mahmodi F, Kadir JB, Puteh A, Pourdad SS et al. 2014 - Genetic diversity and differentiation of Colletotrichum spp. isolates associated with Leguminosae using multigene loci, RAPD and ISSR. The Plant Pathology Journal 30, 10.

Manogaran S, Kannan KP, Mathiyalagan Y. 2017 - Fungal endophytes from Phyllanthus acidus (L.) and Catharanthus roseus (L.). International Research Journal of Pharmacy 8, 86-89.

Marin-Felix Y, Groenewald JZ, Cai L, Chen Q et al. 2017 - Genera of phytopathogenic fungi: GOPHY 1. Studies in Mycology 86, 99-216.

Mathur RS. 1979 - The Coelomycetes of India. Bishen Singh Mahendra Pal Singh, Delhi, India.

Mel'nik VA, Shabunin DA, Popov ES. 2008 - Contributions to the studies of mycobiota in Novgorod and Pskov regions. II. Coelomycetes. Mikologia and Fitopatologia 42, 43-52. [in Russian]

O’Donnell K, Cigelnik E. 1997 - Two divergent intragenomic rDNA ITS2 types within a monophyletic lineage of the fungus Fusarium are nonorthologous. Molecular Phylogeny and Evolution 7, 103-116.

Pai HS. 1966 - A new anthracnose disease of Phyllanthus acidus from India. Plant Disease Reporter 50, 313-314.

Perera RH, Hyde KD, Peršoh D, Jones EBG, Liu ZY. 2018 - Additions to wild seed and fruit fungi 1: The sexual morph of Diaporthe rosae on Magnolia champaca and Senna siamea fruits in Thailand. Mycosphere 9, 256-270.

Prihastuti H, Cai L, Chen H, McKenzie EHC, Hyde KD. 2009 - Characterization of Colletotrichum species associated with coffee berries in Northern Thailand. Fungal Diversity 39, 89-109.

Sakinah MI, Suzianti IV, Latiffah Z. 2014 - Phenotypic and molecular characterization of Colletotrichum species associated with anthracnose of banana (Musa spp.) in Malaysia. Genetics and Molecular Research 13, 3627-3637.

Sharma G, Maymon M, Freeman S. 2017 - Epidemiology, pathology and identification of Colletotrichum including a novel species associated with avocado (Persea americana) anthracnose in Israel. Scientific Reports 7, 15839.

Sharma GUNJAN, Shenoy BD. 2013 - Multigene sequence-based identification of Colletotrichum cymbidiicola, C. karstii and C. phyllanthi from India. Czech Mycology 65, 79-88. 
Shenoy BD, Jeewon R, Lam WH, Bhat DJ et al. 2007 - Morpho-molecular characterization and epitypification of Colletotrichum capsici (Glomerellaceae, Sordariomycetes), the causative agent of anthracnose in chilli. Fungal Diversity 27, 197-211.

Shivas RG, Tan YP, Edwards J, Dinh Q et al. 2016 - Colletotrichum species in Australia. Australasian Plant Pathology 45, 447-464.

Stamatakis A. 2014 - RaxML version 8: a tool for phylogenetic analysis and post-analysis of large phylogenies. Bioinformatics 30, 1312-1313.

Templeton MD, Rikkerink EHA, Solon SL, Crowhurst RN. 1992 - Cloning and molecular characterization of the glyceraldehyde-3-phosphate dehydrogenase encoding gene and cDNA from the plant pathogenic fungus Glomerella cingulata. Gene 122, 225-230.

Thambugala KM, Peršoh D, Perera RH, Hyde KD. 2018 - The genus Pseudodidymosphaeria. Asian Journal of Mycology, in press.

Tharakan ST. 2012 - Taxonomy of the Genus Phyllanthus. In: Kuttan R, Harikumar KB. (Eds.). Phyllanthus species: scientific evaluation and medicinal applications, CRC Press. 3-22.

Thaung MM. 2008 - Biodiversity survey of coelomycetes in Burma. Australasian Mycologist 27, $74-110$.

Tibpromma S, Hyde KD, Jeewon R, Maharachchikumbura SSN et al. 2017 - Fungal diversity notes 491-602: taxonomic and phylogenetic contributions to fungal taxa. Fungal Diversity, 1-261.

Tibpromma S, Hyde KD, Bhat JD, Mortimer PE et al. 2018 - Identification of endophytic fungi from leaves of Pandanaceae based on their morphotypes and DNA sequence data from southern Thailand. MycoKeys 33, 25-67.

Udayanga D, Manamgoda DS, Liu X, Chukeatirote E, Hyde KD. 2013 - What are the common anthracnose pathogens of tropical fruits? Fungal Diversity 61, 165-179.

Weir BS, Damm U, Johnston PR. 2012 - The Colletotrichum gloeosporioides species complex. Studies in Mycology 73, 115-180.

White TJ, Bruns T, Lee S, Taylor JW. 1990 - Amplification and direct sequencing of fungal ribosomal RNA genes for phylogenetics. In: Innis MA, Gelfand DH, Sninsky JJ, White TJ. (Eds.). PCR protocols: a guide to methods and applications. Academic, New York, 315-322.

Wijayawardene NN, Hyde KD, Rajeshkumar KC, Hawksworth DL et al. 2017 - Notes for genera: Ascomycota. Fungal Diversity 86, 1-594.

Wikee S, Cai L, Pairin N, McKenzie EHC et al. 2011 - Colletotrichum species from Jasmine (Jasminum sambac). Fungal Diversity 46, 171-182.

Yang Y, Liu Z, Cai L, Hyde KD. 2012 - New species and notes of Colletotrichum on daylilies (Hemerocallis spp.). Tropical Plant Pathology 37, 165-174.

Zhuang WY. 2001 - Higher Fungi of Tropical China. Mycotaxon, Ltd., Ithaca, NY.

\section{Appendix 1: Supplementary information to manuscript}

\section{Phylogenetic analyses of multi-locus alignments using ARB}

1) ARB (http://www.arb-home.de/) was installed on a QIIME 2 Core VirtualBox Image (v 2017.12, https://qiime2.org/), on which libxm4 and Xfig had been installed previously.

2) Sequences downloaded from GenBank (https://www.ncbi.nlm.nih.gov) were saved shared folder in GenBank format (e.g. ITS.gb).

3) A new ARB database was created using the

- Sequences were imported into the alignment "ali_ITS"

4) The newly created import filter, "GB_MFU.ift" (https://www.arbsilva.de/fileadmin/silva_databases/imp_exp_filters/GB_MFU.ift), was applied to import a maximum of sequence associated information.

5) The newly generated sequences were imported in FASTA format (File > Import > Import from external format)

6) The sequence accession number was preserved.

- The accession was copied to new field called "Acc_ITS" 
i. Sequences with entries in the ali_ITS/data field were searched (Species > Search and query) and the accession numbers were copied using "More functions > Modify Fields of Listed Species" in the "SEARCH and QUERY" window.

7) Imported ITS sequences were aligned using MAFFT (Sequences > Align Sequences > Mafft).

8) A selected sequence was copied to a new 'species' called 'filter' and used as a filter sequence for phylogenetic analyses.

- Positions in the newly created filter sequence, which correspond to ambiguously aligned regions were replaced by Gap symbols ("--").

9) Successive import of sequences from other loci

- A new alignment was created (Sequence > Sequenmce/Alignment Admin) for each additional loci.

- Two databases as,

truncatum complex - ali_ITS, ali_GAPDH, ali_CHS-1, ali_ACT, ali_TUB2

dematium complex - ali_ITS, ali_GAPDH, ali_CHS-1, ali_ACT

- Sequence Accession numbers were copied to the corresponding field, i.e. 'Acc_ITS', 'Acc_GAPDH', 'Acc_CHS1-', 'Acc_ACT' and 'Acc_TUB2' respectively.

- Newly imported sequences were aligned using MAFFT.

- A filter sequence, always called 'filter', was created and modified appropriately (the alignable positions used for the analyses are given in Table 03).

10) Merging of sequences

- A new field ("individual") was created (Species $>$ Database fields admin $>$ create fields...)

- Strain or specimen Ids were copied (using "More functions > Modify Fields of Listed Species" in the "SEARCH and QUERY" window) to the field "individual" and curated.

- $\quad$ Expert mode was enabled (Properties > Toggle expert mode).

- Sequence of the same individual were merged (Species > Merge Species > Create merged species from similar species) using entries in the database field "individual" as identifier.

- The newly created field "merged_species" was modified by adding a " 1 " to those individuals (strain or specimens) which are only represented by a single sequence.

- Database entries with single sequences were deleted; i.e. species having no entry in the "merged_species" field were searched (Species $>$ Search and query) and deleted (Delete Listed).

11) Calculating phylogenetic trees using RAxML for single loci.

- Only positions in which the filter sequence has no Gap (“-”) were considered for phylogenetic reconstructions.

- Parameters - GTRGAMMA+I model of rate distribution, 1,000 replicates

- The resulted trees were renamed.

- To assure traceability of the analyses, the alignment (including the filter sequence) underlying the phylogenetic tree was copied to a new alignment, which was renamed including the name of the corresponding tree.

12) Calculating multi-locus phylogenies.

- Single loci alignments (including the filter sequences) were concatenated (Sequence $>$ Concatenate Sequences/Alignments).

- Phylogenetic trees were calculated as detailed above based on the positions specified by the filter sequence.

- Concatenated trees were obtained using RAxML and MRBAYES. 
- Trees were renamed and the underlying alignment copied to a correspondingly named alignment for documentation.

13) Deposition of the databases in SILVA project website

- (https://www.arb-silva.de/no_cache/download/archive/publications/fungal_taxa/). 